\title{
Somato-axodendritic release of oxytocin into the brain due to calcium amplification is essential for social memory
}

\author{
Haruhiro Higashida ${ }^{1,2}$
}

Received: 21 October 2015/Accepted: 28 October 2015/Published online: 19 November 2015

(C) The Author(s) 2015. This article is published with open access at Springerlink.com

\begin{abstract}
Oxytocin (OT) is released into the brain from the cell soma, axons, and dendrites of neurosecretory cells in the hypothalamus. Locally released OT can activate OT receptors, form inositol-1,4,5-trisphosphate and elevate intracellular free calcium $\left(\mathrm{Ca}^{2+}\right)$ concentrations $\left[\left(\mathrm{Ca}^{2+}\right)_{i}\right]$ in self and neighboring neurons in the hypothalamus, resulting in further OT release: i.e., autocrine or paracrine systems of OT-induced OT release. CD38-dependent cyclic ADP-ribose (cADPR) is also involved in this autoregulation by elevating $\left[\mathrm{Ca}^{2+}\right]_{i}$ via $\mathrm{Ca}^{2+}$ mobilization through ryanodine receptors on intracellular $\mathrm{Ca}^{2+}$ pools that are sensitive to both $\mathrm{Ca}^{2+}$ and cADPR. In addition, it has recently been reported that heat stimulation and hyperthermia enhance $\left[\mathrm{Ca}^{2+}\right]_{i}$ increases by $\mathrm{Ca}^{2+}$ influx, probably through TRPM2 cation channels, suggesting that cADPR and TRPM2 molecules act as $\mathrm{Ca}^{2+}$ signal amplifiers. Thus, OT release is not simply due to depolarization-secretion coupling. Both of these molecules play critical roles not only during labor and milk ejection in reproductive females, but also during social behavior in daily life in both genders. This was clearly demonstrated in CD38 knockout mice in that social behavior was impaired by reduction of $\left[\mathrm{Ca}^{2+}\right]_{i}$ elevation and subsequent OT secretion. Evidence for the associations of CD38 with social behavior and
\end{abstract}

Haruhiro Higashida

haruhiro@med.kanazawa-u.ac.jp

1 Department of Basic Research on Social Recognition, Research Center for Child Mental Development, Kanazawa University, Kanazawa 920-8640, Japan

2 Division of Socio-Cognitive-Neuroscience, Osaka University United Graduate School for Child, The Kanazawa Branchi, Takara-machi 13-1, Kanazawa 920-8640, Japan psychiatric disorder is discussed, especially in subjects with autism spectrum disorder.

Keywords Oxytocin - Hypothalamus - Social behavior * CD38 - TRPM2

\section{Introduction}

Oxytocin (OT) and arginine vasopressin (AVP) are nonapeptides that differ in two amino acid residues [1]. OT and AVP are synthesized mostly in distinct neurons in the paraventricular nucleus (PVN) and supraoptic nucleus (SON) in the hypothalamus $[2,3]$. OT and AVP are secreted into the blood circulation and have physiological roles in peripheral organs, such as the uterus, mammary gland, and kidney. They induce contraction of uterine and mammary duct smooth muscle or diuretic action in the kidney as hormones [4-6].

OT, AVP, and their receptors are present in the brain not only in females during specific reproductive periods but also in non-reproductive females and males [6]. Accumulating evidence has established that, in addition to classical hormonal functions, both peptides play critical roles in social recognition and social behavior in mammals, including humans [7-20]. This review focuses mainly on OT. The main point is not a general functional role of OT in a comprehensive review, but the molecular mechanisms of OT secretion into the brain that is critical in the neuronal function of OT in social recognition and behavior $[4,11$, $13,21]$.

Another reason to focus on the release is that the mechanism contains a very important aspect in terms of physiological science, in that the proposed idea challenges the principal rule in physiology of depolarization-secretion 
coupling [22-24]. Furthermore, this mechanism seems to have a potential relationship to autism spectrum disorder (ASD), a serious developmental disorder, which is a rapidly advancing field in neuroscience and psychiatry and is a serious disorder in our society [25-28]. There have been many reviews regarding the relationship between ASD and OT [29-35]. However, there have been few regarding the molecular mechanism of OT release into the brain [4], which is the critical step for social recognition and social behavior [26-28].

\section{Somato-axodendritic release of oxytocin}

OT is secreted from the nerve terminals of axons of oxytocinergic neurons at the perivascular site in the posterior lobe of the pituitary into the circulation [4] (Fig. 1). Oxytocinergic neurons send their axons to the amygdala and some other limited brain regions and secrete OT from the nerve terminals $[4,12,15]$. It is known that adrenaline stimulates oxytocinergic neurons in the SON, which results in local release of OT in the brain [5, 36]. This release occurs from the cell soma, axons, and dendrites, i.e., somato-axodendritic release [37-39].

Locally released OT causes excitation of OT neurons by activating OT receptors expressed in neurons of both the PVN and SON [40-43]. OT stimulates OT receptors and facilitates OT release from the stimulated neurons. Released OT can stimulate OT receptors and elicits release from the same neurons (autocrine) or nearby neurons (paracrine) [44] (Fig. 2). This OT-induced OT release determines the basal brain concentrations and elevated concentrations of OT. The concept of autoregulation, OTinduced OT release, can be an extremely efficient way to achieve massive OT recruitment during uterine contraction in labor and milk ejection in lactation [5, 6, 45-47]. Autoregulation, however, is also an essential brain mechanism for social recognition in daily life in both genders, as proposed previously $[25,27,28]$.

\section{Oxytocin receptors and cellular signaling}

OT receptors are seven-transmembrane proteins that couple with the $\mathrm{G}_{\mathrm{q} / 11^{1}}$-type GTP-binding protein [48]. Stimulation of OT receptors leads to the production of inositol1,4,5-trisphosphate $\left(\mathrm{IP}_{3}\right)$ and diacylglycerol (DAG) through the activation of phospholipase C (PLC) [48]. This results in activation of $\mathrm{Ca}^{2+}$ mobilization from $\mathrm{IP}_{3}$-sensitive $\mathrm{Ca}^{2+}$ pools [49].

On the other hand, another $\mathrm{Ca}^{2+}$ signal pathway of cyclic ADP-ribose (cADPR) [50, 51] was identified downstream of OT receptors [11]. cADPR mobilizes $\mathrm{Ca}^{2+}$ through cADPR-sensitive $\mathrm{Ca}^{2+}$ pools, in a mechanism referred to as $\mathrm{Ca}^{2+}$-induced $\mathrm{Ca}^{2+}$ release. In this process, cADPR plays an essential role in mobilizing $\mathrm{Ca}^{2+}$ through $\mathrm{Ca}^{2+}$ channels of ryanodine receptors [52-56] (Fig. 3). The recent review by Leng et al. did not mention this cADPR/ CD38 hypothesis [4], probably because they described by their data based on their finding with thapsigargin [36].

It is known that intracellular cADPR concentrations are regulated in many different ways, including activation of ADP-ribosyl cyclase or CD38, via heterotrimeric GTPbinding proteins, or phosphorylation downstream of the $\mathrm{G}$
Fig. 1 Electron micrographs of the posterior pituitary glands of wild-type (a) and CD38

knockout (b) mice. Vesicles are nerve endings close to the vascular space $(\mathrm{V})$. Most of the dense core vesicles are oxytocinergic, as determined by immunoelectron microscopic examination. The nerve endings of CD38 knockout mice contain more vesicles than those of wild-type mice, indicating that vesicles are released in the wildtype mice and not secreted in CD38 knockout mice. Bar $500 \mathrm{~nm}$ (modified from Fig. 3 of Ref. [21]) (a)

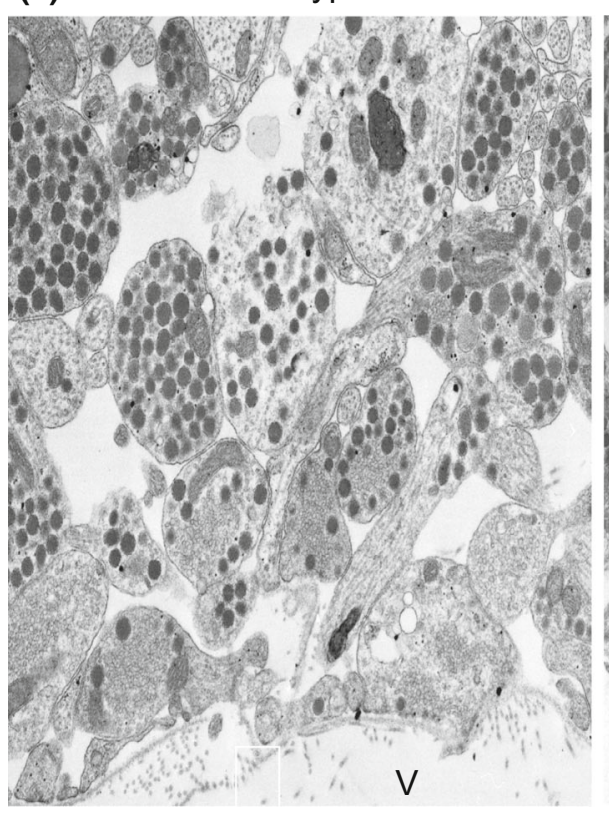

(b) $\quad \mathrm{CD} 38 \mathrm{KO}$

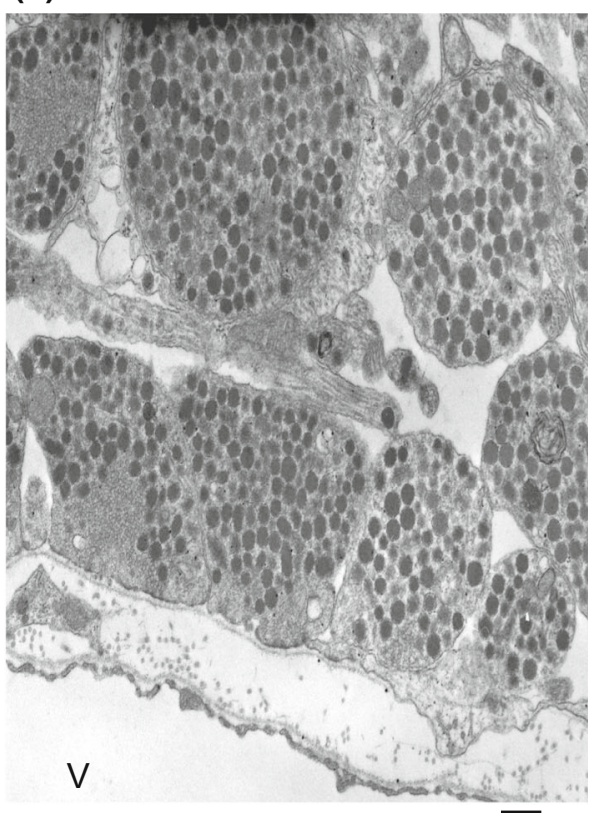




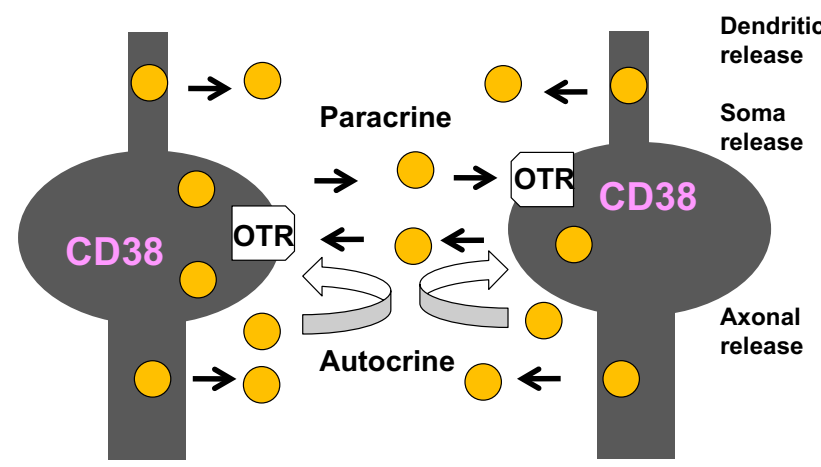

Fig. 2 Scheme showing autocrine and paracrine release of oxytocin. OT is released from dendrites (dendritic release), from the cell soma (soma release), and from axons (axonal release) in the hypothalamus. Hypothalamic oxytocinergic neurons express OT receptors (OTR). Released OT binds to OTR. More OT (yellow circle) is released by CD38-mediated intracellular calcium amplification (not shown). The positive feedback of OT release occurs by OT released from self or nearby cells via autocrine and paracrine mechanisms, respectively

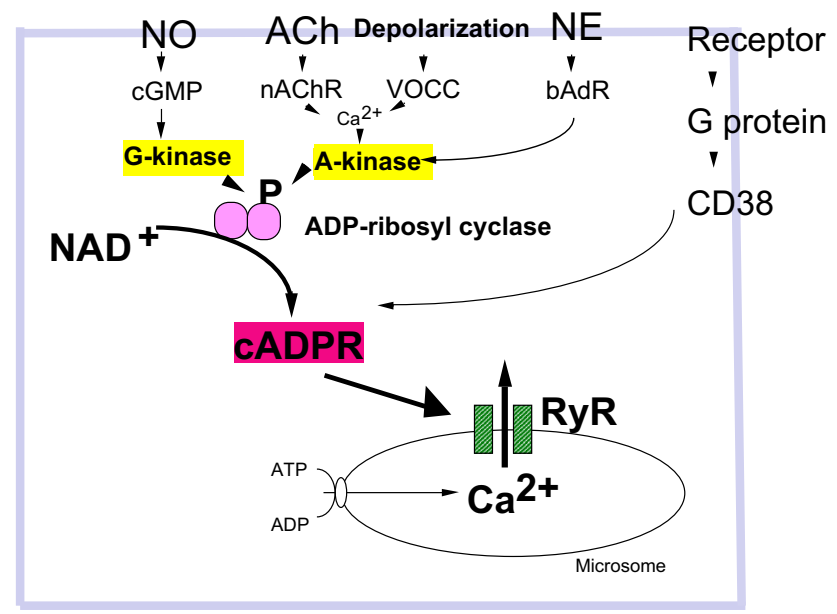

Fig. 3 Intracellular signaling pathways leading to increased cyclic ADP-ribose formation. Phosphorylation (P) of ADP-ribosyl cyclase (pink) is mediated by several pathways. Nitric oxide (NO), cyclic GMP (cGMP), and protein kinase G (G-kinase); acetylcholine (ACh), nicotinic $\mathrm{ACh}$ receptors (nAChR); voltage-operated $\mathrm{Ca}^{2+}$ channels (VOCC), $\mathrm{Ca}^{2+}$ and protein kinase A (A-kinase); norepinephrine (NE), $\beta$ adrenaline receptors (bAdR). Activation of CD38 by GTP-binding protein ( $\mathrm{G}$ protein) and various types of receptors triggers formation of cADPR. cADPR opens $\mathrm{Ca}^{2+}$ release channels of ryanodine receptor type II or III (RyR) with another cofactor, $\mathrm{Ca}^{2+}$ (not shown). Mobilization of $\mathrm{Ca}^{2+}$ from microsomes of $\mathrm{Ca}^{2+}$ pools increases $\left[\mathrm{Ca}^{2+}\right]_{i}$, resulting in OT release (not shown)

protein-coupled receptor signaling pathways [57-59]. Specifically, the activation of ADP-ribosyl cyclase or CD38 by cyclic GMP- or cyclic AMP-dependent protein kinases has been reported in Aplysia californica, liver cells $[60,61]$, LAK cells [62, 63], and artery smooth muscle cells [57] (Fig. 3).

cADPR is a catalytic product of ADP-ribosyl cyclase or ectopic CD38 [50, 51, 63] (Fig. 4). cADPR is produced in the extracellular space by the large C-terminal portion of CD38 with catalytic activity that may be present in the extracellular space. Therefore, it is unclear how extracellular cADPR produced by CD38 acts as an intracellular second messenger. It has been reported that cADPR applied extracellularly stimulates intracellular ryanodine receptors after internalization by the nucleotide-transporting capacity of CD38 in fibroblasts and astrocytes (the nucleotide carrier hypothesis of De Flora) [64, 65]. Recently, it was reported that the type II transmembrane glycoprotein, CD38, may exist in two forms with regard to membrane topology [66, 67]; the large C-terminal portion with catalytic activity may exist in the extracellular space as the type II protein, and this catalytic site may also exist inside the cell as the type III form (Fig. 4a). In the latter case, the product of $\mathrm{CD} 38$, cADPR, is produced intracellularly, and acts directly as a second messenger (two topology hypothesis of Lee).

\section{Effects of oxytocin on ADP-ribosyl cyclase and intracellular $\mathrm{Ca}^{2+}$ concentrations}

Application of OT stimulates ADP-ribosyl cyclase activity or CD38 in crude membrane fractions, when measured by cADPR formation from $\beta-\mathrm{NAD}^{+}$or by cyclic GDP-ribose (cGDPR) production from $\mathrm{NGD}^{+}[50,68]$. cADPR or cGDPR production increases in a concentration-dependent manner upon exposure to sub-nanomolar concentrations of OT [49].

Subsequently, in isolated hypothalamic neurons, application of $100 \mathrm{pM}$ OT results in $\left[\mathrm{Ca}^{2+}\right]_{i}$ increases: a rapid initial increase and a sustained elevation lasting for $5 \mathrm{~min}$ [69]. OT elicits an initial elevation of the maximum $\left[\mathrm{Ca}^{2+}\right]_{i}$, and this phase is $\mathrm{IP}_{3}$-dependent. Pretreatment with 8-bromo-cADPR, an antagonist of the cADPR-binding site of $\mathrm{Ca}^{2+}$ release channels of ryanodine, inhibits OT-mediated sustained $\left[\mathrm{Ca}^{2+}\right]_{i}$ increases. ADPR and $\beta-\mathrm{NAD}^{+}$also induce elevation of $\left[\mathrm{Ca}^{2+}\right]_{i}$ and replicate the second phase of sustained $\left[\mathrm{Ca}^{2+}\right]_{i}$ increases $[49,69]$. Under $\mathrm{Ca}^{2+}$-free conditions, the OT-mediated increase of $\left[\mathrm{Ca}^{2+}\right]_{i}$ shows little change in either phase, suggesting that the two phases of $\left[\mathrm{Ca}^{2+}\right]_{i}$ elevation in hypothalamic neurons are due to $\mathrm{Ca}^{2+}$ mobilization from the intracellular $\mathrm{Ca}^{2+}$ pools [49].

\section{Oxytocin release by extracellular application of cyclic ADP-ribose}

High potassium-induced depolarization produces an increase of up to eightfold in OT secretion from isolated mouse hypothalamic neurons or their axon terminals in the posterior pituitary gland, respectively [21]. OT release is 


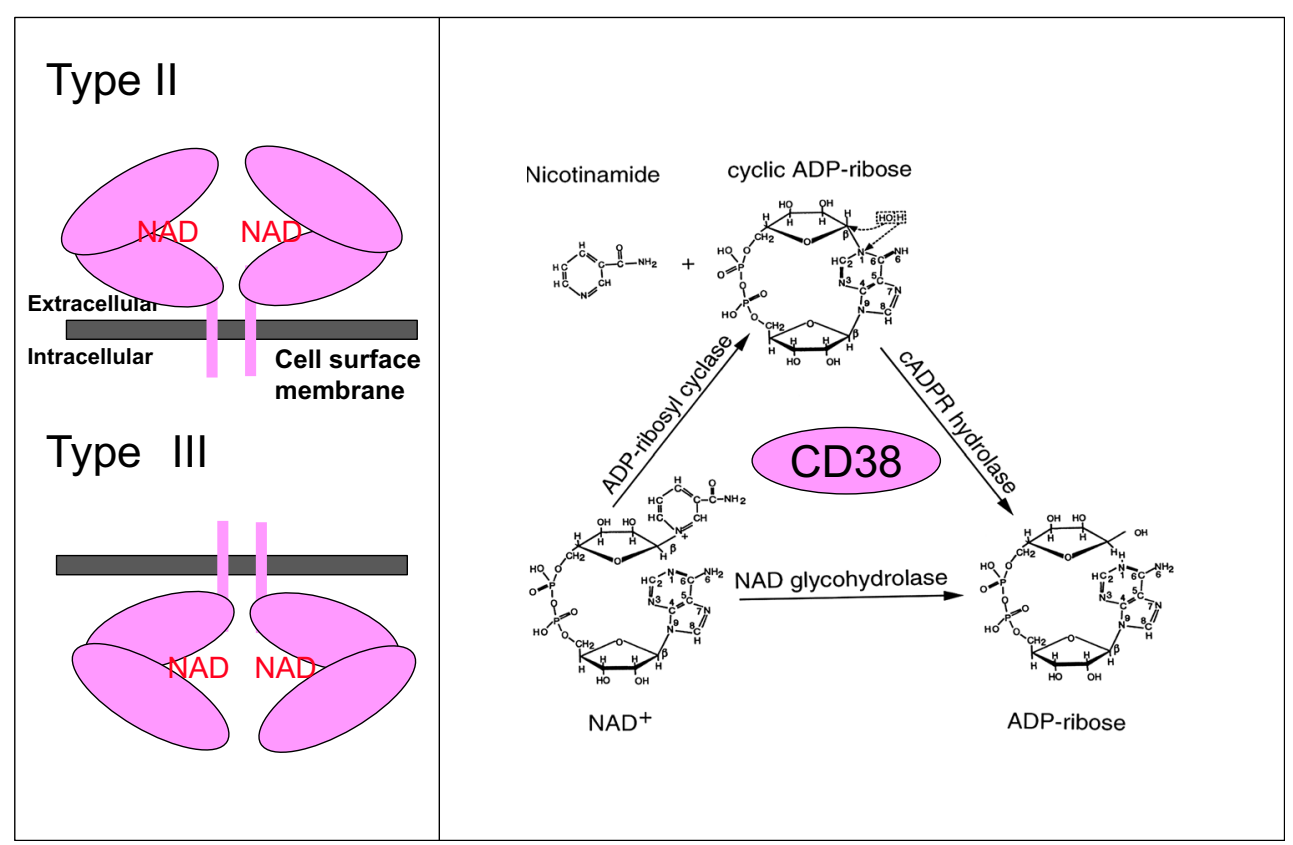

Fig. 4 Membrane topology and enzyme reaction of CD38. CD38 (pink oval) usually forms a dimer. $\beta-\mathrm{NAD}^{+}$binds to the central catalytic site of CD38. The large C-terminal part is located in the extracellular space, as the type II transmembrane protein, or intracellular space as the type III transmembrane protein, according to Lee and colleagues $[66,67]$. CD38 has three enzymic activities.

enhanced by about fourfold by application of extracellular $\beta-\mathrm{NAD}^{+}$, a precursor of cADPR (refer to Fig. 4 in [21]). The increase is blocked completely by 8 -bromo-cADPR. To further confirm the involvement of cADPR, we examined the effects of extracellular application of several $\beta$ $\mathrm{NAD}^{+}$metabolites [49, 69]. Only cADPR showed a potentiation effect, indicating that OT release utilizes the cADPR/ryanodine calcium amplification system (Fig. 5).

\section{Involvement of TRPM2 channels}

Melastatin-related transient receptor potential channel 2 (TRPM2, previously named TRPC7 or LTRPC2) possesses ADPR hydrolase activity and is a $\mathrm{Ca}^{2+}$-permeable cation channel. $\beta$-NAD ${ }^{+}, \mathrm{ADPR}$, and cADPR can activate TRPM2 channels [70]. TRPM2 activation by cADPR is promoted at body temperature $\left(>35^{\circ} \mathrm{C}\right)$ and is involved in insulin secretion in pancreatic $\beta$ cells [71]. In addition, TRPM2 channels are related to receptor functions through cADPR formation [72].

Extracellularly applied cADPR can activate $\left[\mathrm{Ca}^{2+}\right]_{i}$ signaling via CD38 or TRPM2 channels downstream of OT receptors. $\left[\mathrm{Ca}^{2+}\right]_{i}$ increases in the model neuron, NG10815 mouse neuroblastoma $\times$ rat glioma hybrid cells that possess CD38 [58, 73] but not OT receptors [74], as in the isolated whole hypothalamus after stimulation with
CD38 catalyzes formation of cyclic ADP-ribose from $\beta-\mathrm{NAD}^{+}$by cleaving nicotinamide. cADPR is hydrolyzed to form ADP-ribose. $\beta-\mathrm{NAD}^{+}$also has $\mathrm{NAD}^{+}$glycohydrolase activity to form ADP-ribose from $\beta-\mathrm{NAD}^{+}$in one step. The scheme of enzyme activity is modified from Lee [50]

extracellularly applied cADPR [69, 75]. Interestingly, the same tissues show significantly greater increases upon extracellular challenge with cADPR together by heating to $40{ }^{\circ} \mathrm{C}$ from $35{ }^{\circ} \mathrm{C}$ in the incubation medium (Fig. 6). Little or no cADPR-mediated $\left[\mathrm{Ca}^{2+}\right]_{i}$ elevation was observed at $40{ }^{\circ} \mathrm{C}$ in the absence of extracellular $\mathrm{Ca}^{2+} \cdot \mathrm{Ca}^{2+}$ influx is expected, probably through non-selective cation TRPM2 channels, because elevation of $\left[\mathrm{Ca}^{2+}\right]_{i}$ is inhibited by the TRPM2 channel inhibitor, 2-aminoethoxydiphenyl borate (2-APB). Similarly, 8-bromo-cADPR inhibits responses to $\beta-\mathrm{NAD}^{+}$and heat. These results suggest that $\mathrm{cADPR}$ contributes to both $\mathrm{Ca}^{2+}$ mobilization from internal $\mathrm{Ca}^{2+}$ pools and $\mathrm{Ca}^{2+}$ influx through TRPM2 $\mathrm{Ca}^{2+}$-permeable channels from the extracellular space. Such $\left[\mathrm{Ca}^{2+}\right]_{i}$ increases may result in OT release. However, there have been no previous reports regarding heat-induced OT release in the hypothalamus.

\section{Contribution of CD38}

In the central nervous system, ADP-ribosyl cyclase activity corresponding to CD38 is detected as early as embryonic day 15 in mouse development [76]. In the brain, expression levels of CD38 and ADP-ribosyl cyclase activity increase with further development [77]. The role of CD38 in 


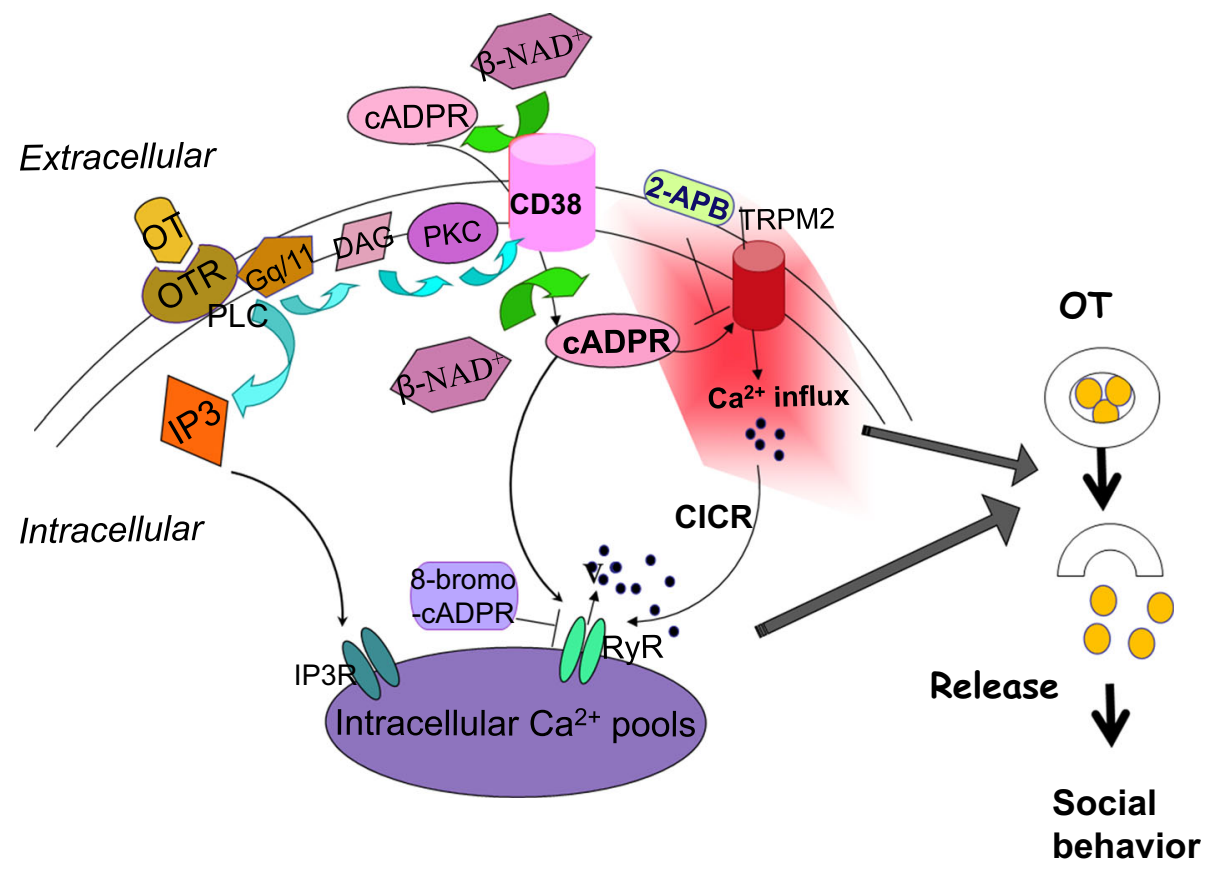

Fig. 5 Oxytocin induced oxytocin release. Oxytocin (OT; yellow circles) stimulates oxytocin receptors (OTR). Subsequently, the $\mathrm{G}_{\mathrm{q} / 11}$ type $\mathrm{G}$ protein and phospholipase C (PLC) are activated, resulting in formation of inositol-1,4,5-trisphosphate (IP3) and diacylglycerol (DAG). Stimulated protein kinase C (PKC) activates CD38 and increases formation of $\mathrm{cADPR}$ from $\beta-\mathrm{NAD}^{+}$inside or outside cells. cADPR activates $\mathrm{Ca}^{2+}$ influx TRPM2 cation channels.

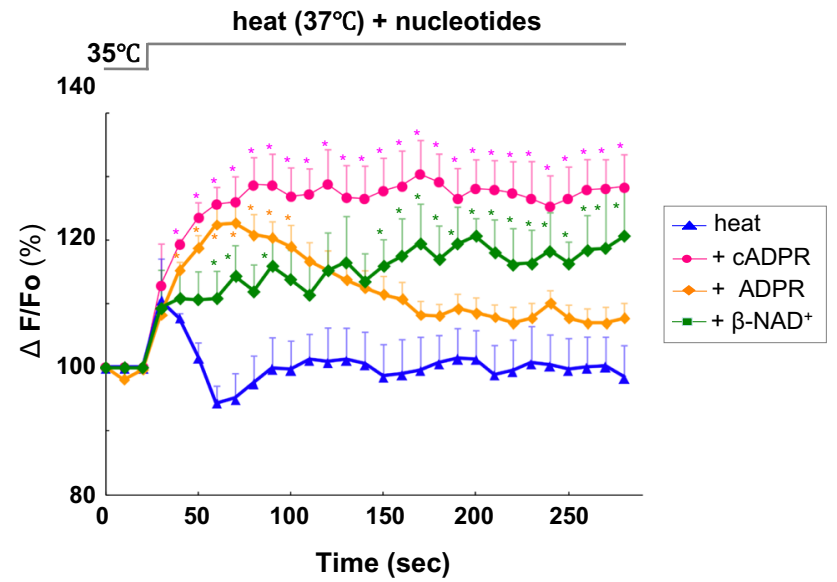

Fig. 6 Effects of cyclic ADP-ribose, ADP-ribose, and $\beta-\mathrm{NAD}^{+}$on heat-induced calcium concentration rise. Time course of $\left[\mathrm{Ca}^{2+}\right]_{i}$ changes in Oregon Green-induced anterior hypothalamic neurons. At about $25 \mathrm{~s}$ after the beginning of each trace, cells were heated from 35 to $37{ }^{\circ} \mathrm{C}$ together with $100 \mu \mathrm{M}$ cADPR, ADPR, $\beta-\mathrm{NAD}^{+}$or without nucleotides (heat alone). Symbols indicate changes in $\left[\mathrm{Ca}^{2+}\right]_{i}$ levels, represented by the fluorescence intensity at each time point relative to resting intensity at time zero. $N=3-5$ experiments. Mean \pm SEM. Modified from [69]
2-Aminoethoxydiphenyl borate (2-APB) inhibits TRPM2 channels. IP3 induces mobilization of $\mathrm{Ca}^{2+}$. TRPM2 mediates $\mathrm{Ca}^{2+}$ influx, which also stimulates $\mathrm{Ca}^{2+}$ mobilization through ryanodine receptor $\mathrm{Ca}^{2+}$ release channels as a cofactor together with cADPR. These $\mathrm{Ca}^{2+}$ ions (filled circles) increased by $\mathrm{Ca}^{2+}$ amplification mechanisms stimulate OT (yellow) release into the brain, which is an essential step for social memory and social behavior. Modified from [11, 27, 52, 73]

regulation of OT secretion through cADPR-mediated intracellular calcium signaling has been clearly demonstrated using CD38 knockout mice [11, 21, 78, 79]. The plasma and cerebrospinal fluid OT levels are reduced in CD38 knockout mice. Electron microscopic examination exhibited little to no release from the nerve endings of oxytocinergic neurons in the pituitary of CD38 knockout mice (Fig. 1). These phenotypes were rescued by simple subcutaneous injection of OT as well as brain local reexpression of human CD38, but not mutant CD38, by the lentivirus infection method in CD38 knockout mice [21].

\section{Human social behavior and psychiatric disorders}

As CD38 is recognized as being closely related to OT release and social memory in mice, we examined the association of single nucleotide polymorphisms (SNPs) in the human CD38 gene on ASD [80]. In a series of elegant studies in 323 mothers, fathers, and non-parents, Epstein and colleagues reported that risk alleles on CD38 
(including rs3796863) genes are associated with less parental touch. In contrast, relatively high plasma OT levels in subjects with low-risk $C D 38$ alleles predict longer durations of parent-infant gaze synchrony. Furthermore, parents that display more touch toward their infants were reported to have been well cared for in childhood, to exhibit higher plasma to levels, and to have lowrisk $C D 38$ alleles $[29,30,81]$. The mother's $C D 38$ allele predicts parental behavioral synchrony at 1 and 6 months of their first-born infants and children's social reciprocity during interactions with their best friend at 3 years. CD38 in the OT pathway was shown to be critical for parentinfant attachment and attention [82]. A SNP on the $C D 38$ gene is also associated with social integration and social connectedness [83].

Several studies indicated the association of $C D 38$ with ASD [84-87]. Ten SNPs and mutations of CD38 were examined, and the $C D 38$ SNPs, rs6449197 and rs3796863, were shown to be linked with high-functioning ASD in participants in the USA but not in Japan. These findings were partially replicated among Israeli subjects $[29,31,32$, 87].

\section{Conclusion}

This review discussed how OT is released into the brain. $\mathrm{Ca}^{2+}$ influx through $\mathrm{Ca}^{2+}$ channels is not sufficient to trigger OT release. The $\mathrm{Ca}^{2+}$ signal must be amplified by $\mathrm{Ca}^{2+}$-induced $\mathrm{Ca}^{2+}$ release through $\mathrm{Ca}^{2+}$ channels of ryanodine receptors type II or III by cADPR and some NAD metabolites in the hypothalamus (Fig. 7). In addition, $\mathrm{Ca}^{2+}$ influx through TRPM2 channels contribute more to increases in $\left[\mathrm{Ca}^{2+}\right]_{i}$. This hypothesis of depolarization-

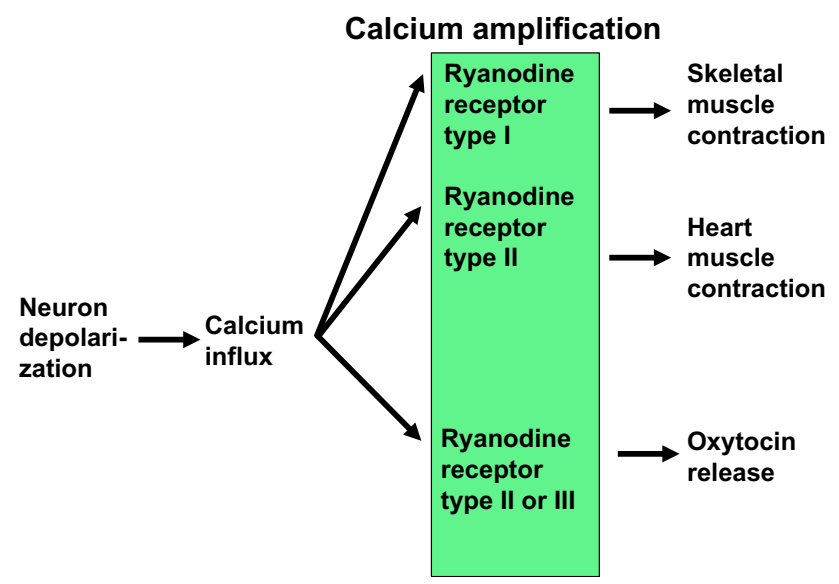

Fig. 7 Scheme indicating $\mathrm{Ca}^{2+}$ amplification with different ryanodine receptor subtypes. Skeletal muscle contraction and heart muscle contraction utilize type I and II ryanodine receptors, respectively. Oxytocin release uses type II or III ryanodine receptors independent but heat-sensitive $\mathrm{Ca}^{2+}$ signaling for OT release is consistent with the previous suggestion of dendritic release of OT without depolarization [4, 21, 39].

OT exerts an anxiolytic effect during stress, and stress sometimes induces hyperthermia. It is therefore interesting to examine how stress induces hyperthermia, which results in subsequent OT release. OT release seems to be important in damping the stress-induced disadvantage.

OT is an essential molecule for social memory and social behavior [21, 29]. Deficiency in social behavior is the core symptom of ASD. Recently, Yamasue and his group reported that repetitive intranasal OT administration for 6 weeks improved symptoms of the social behavior domain [88]. This result could be due to the delivery of OT to the brain by intranasal administration, but there is still little direct evidence regarding whether OT is recruited into the brain from the peripheral tissues or organs crossing the blood-brain barrier from the blood circulation. Several important questions regarding OT secretion into the brain and OT-induced $\mathrm{Ca}^{2+}$ signaling and OT transport from the blood to the brain remain to be resolved.

Acknowledgments This work was supported by a grant-in-aid from Integrated Research on Neuropsychiatric Disorders carried out under the Strategic Research Program for Brain Sciences.

Open Access This article is distributed under the terms of the Creative Commons Attribution 4.0 International License (http://crea tivecommons.org/licenses/by/4.0/), which permits unrestricted use, distribution, and reproduction in any medium, provided you give appropriate credit to the original author(s) and the source, provide a link to the Creative Commons license, and indicate if changes were made.

\section{References}

1. Hoyle CH (1998) Neuropeptide families: evolutionary perspectives. Regul Pept 73(1):1-33

2. Gainer H (2012) Cell-type specific expression of oxytocin and vasopressin genes: an experimental odyssey. J Neuroendocrinol 24(4):528-538

3. Katoh A et al (2011) Highly visible expression of an oxytocinmonomeric red fluorescent protein 1 fusion gene in the hypothalamus and posterior pituitary of transgenic rats. Endocrinology 152(7):2768-2774

4. Leng $\mathrm{G}$ et al (2015) 60 years of neuroendocrinology: the posterior pituitary, from Geoffrey Harris to our present understanding. J Endocrinol 226(2):T173-T185

5. Douglas AJ, Leng G, Russell JA (2002) The importance of oxytocin mechanisms in the control of mouse parturition. Reproduction 123(4):543-552

6. Brunton PJ, Russell JA (2010) Endocrine induced changes in brain function during pregnancy. Brain Res 1364:198-215

7. Carter CS (2003) Developmental consequences of oxytocin. Physiol Behav 79(3):383-397

8. Kosfeld $\mathrm{M}$ et al (2005) Oxytocin increases trust in humans. Nature 435(7042):673-676

9. Donaldson ZR, Young LJ (2008) Oxytocin, vasopressin, and the neurogenetics of sociality. Science 322(5903):900-904 
10. Ebstein RP, Israel S, Lerer E (2009) Arginine vasopressin and oxytocin modulate human social behavior. Ann N Y Acad Sci 1167:87-102

11. Higashida $\mathrm{H}$ et al (2010) Oxytocin signal and social behaviour: comparison among adult and infant oxytocin, oxytocin receptor and CD38 gene knockout mice. J Neuroendocrinol 22(5):373-379

12. Neumann I et al (1996) Oxytocin released within the supraoptic nucleus of the rat brain by positive feedback action is involved in parturition-related events. J Neuroendocrinol 8(3):227-233

13. Neumann ID (2008) Brain oxytocin: a key regulator of emotional and social behaviours in both females and males. J Neuroendocrinol 20(6):858-865

14. Onaka T, Takayanagi Y, Yoshida M (2012) Roles of oxytocin neurones in the control of stress, energy metabolism, and social behaviour. J Neuroendocrinol 24(4):587-598

15. Insel TR (2010) The challenge of translation in social neuroscience: a review of oxytocin, vasopressin, and affiliative behavior. Neuron 65(6):768-779

16. Yoshimura M, Uezono Y, Ueta Y (2015) Anorexia in human and experimental animal models: physiological aspects related to neuropeptides. J Physiol Sci 65(5):385-395

17. Nagasawa $\mathrm{M}$ et al (2015) Social evolution. Oxytocin-gaze positive loop and the coevolution of human-dog bonds. Science 348(6232):333-336

18. Choleris E et al (2009) Neuroendocrinology of social information processing in rats and mice. Front Neuroendocrinol 30(4):4424-4459

19. Meyer-Lindenberg A et al (2011) Oxytocin and vasopressin in the human brain: social neuropeptides for translational medicine. Nat Rev Neurosci 12(9):524-538

20. Takayanagi Y et al (2005) Pervasive social deficits, but normal parturition, in oxytocin receptor-deficient mice. Proc Natl Acad Sci USA 102(44):16096-16101

21. Jin D et al (2007) CD38 is critical for social behaviour by regulating oxytocin secretion. Nature 446(7131):41-45

22. Bourque CW (1991) Activity-dependent modulation of nerve terminal excitation in a mammalian peptidergic system. Trends Neurosci 14(1):28-30

23. Katz B (1969) The release of neural substances, Sherrington Lecture. Liverpool University, Liverpool, p 47

24. Augustine GJ, Neher E (1992) Calcium requirements for secretion in bovine chromaffin cells. J Physiol 450:247-271

25. Salmina AB et al (2013) Integrative neurochemistry and neurobiology of social recognition and behavior analyzed with respect to CD38-dependent brain oxytocin secretion. Curr Top Med Chem 13(23):2965-2977

26. Lopatina $\mathrm{O}$ et al (2013) The roles of oxytocin and CD38 in social or parental behaviors. Front Neurosci 6:182

27. Higashida $\mathrm{H}$ et al (2012) CD38 and its role in oxytocin secretion and social behavior. Horm Behav 61(3):351-358

28. Higashida $\mathrm{H}$ et al (2012) Social memory, amnesia, and autism: brain oxytocin secretion is regulated by $\mathrm{NAD}^{+}$metabolites and single nucleotide polymorphisms of CD38. Neurochem Int 61(6):828-838

29. Feldman R et al (2015) Oxytocin pathway genes: evolutionary ancient system impacting on human affiliation, sociality, and psychopathology Biol Psychiatry pii: S0006-3223(15)00656-3

30. Feldman R et al (2012) Sensitive parenting is associated with plasma oxytocin and polymorphisms in the OXTR and CD38 genes. Biol Psychiatry 72(3): 175-181

31. Riebold $M$ et al (2011) All-trans retinoic acid upregulates reduced CD38 transcription in lymphoblastoid cell lines from autism spectrum disorder. Mol Med 17(7-8):799-806
32. Lerer E et al (2010) Low CD38 expression in lymphoblastoid cells and haplotypes are both associated with autism in a familybased study. Autism Res 3(6):293-302

33. Guastella AJ, Hickie IB (2015) Oxytocin treatment, circuitry and autism: a critical review of the literature placing oxytocin into the autism context. Biol Psychiatry pii: S0006-3223(15)00543-0

34. Yamasue $\mathrm{H}$ et al (2012) Integrative approaches utilizing oxytocin to enhance prosocial behavior: from animal and human social behavior to autistic social dysfunction. J Neurosci 32(41):14109-14117

35. Ebstein RP (2012) The contributions of oxytocin and vasopressin pathway genes to human behavior. Horm Behav 61(3):359-379

36. Tobin VA et al (2008) The effects of apelin on the electrical activity of hypothalamic magnocellular vasopressin and oxytocin neurons and somatodendritic peptide release. Endocrinology 149(12):6136-6145

37. Bealer SL, Armstrong WE, Crowley WR (2010) Oxytocin release in magnocellular nuclei: neurochemical mediators and functional significance during gestation. Am J Physiol Regul Integr Comp Physiol 299(2):R452-R458

38. Grinevich V (2015) Assembling the puzzle: pathways of oxytocin signaling in the brain. Biol Psychiatry pii: S0006-3223(15)003510

39. Ludwig M, Leng G (2006) Dendritic peptide release and peptidedependent behaviours. Nat Rev Neurosci 7(2):126-136

40. Neumann ID (2007) Stimuli and consequences of dendritic release of oxytocin within the brain. Biochem Soc Trans 35(Pt 5):1252-1257

41. Adan RAH et al (1995) Rat oxytocin receptor in brain, pituitary, mammary gland, and uterus: partial sequence and immunocytochemical localization. Endocrinology 136(9):4022-4028

42. Freund-Mercier MJ, Stoeckel ME, Klein MJ (1994) Oxytocin receptors on oxytocin neurons: histoautoradiographic detection in the lactating rat. J Physiol (Lond) 480:155-161

43. Young LJ et al (1997) Changes in oxytocin receptor mRNA in rat brain during pregnancy and the effects of estrogen and interleukin-6. J Neuroendocrinol 9(11):859-865

44. Ludwig M, Stern J. (2015) Multiple signalling modalities mediated by dendritic exocytosis of oxytocin and vasopressin. Philos Trans R Soc Lond B Biol Sci:370(1672) pii: 20140182

45. Richard P, Moos F, Freund-Mercier MJ (1991) Central effects of oxytocin. Physiol Rev 71(2):331-370

46. Moos F et al (1984) Release of oxytocin and vasopressin by magnocellular nuclei in vitro: specific facilitatory effect of oxytocin on its own release. J Endocrinol 102(1):63-72

47. Neumann I et al (1994) An oxytocin receptor antagonist infused into the supraoptic nucleus attenuates intranuclear and peripheral release of oxytocin during suckling in conscious rats. Endocrinol 134:141-148

48. Gimpl G, Fahrenholz F (2001) The oxytocin receptor system: structure, function, and regulation. Physiol Rev 81(2):629-683

49. Lopatina $\mathrm{O}$ et al (2010) Oxytocin-induced elevation of ADPribosyl cyclase activity, cyclic ADP-ribose or $\mathrm{Ca}^{2+}$ concentrations is involved in autoregulation of oxytocin secretion in the hypothalamus and posterior pituitary in male mice. Neuropharmacology 58(1):50-55

50. Lee HC (2012) The cyclic ADP-ribose/NAADP/CD38-signaling pathway: past and present. Messenger 1(1):16-33

51. Okamoto H, Takasawa S, Akira Sugawara A (2014) The CD38cyclic ADP-ribose system in mammals: historical background, pathophysiology and perspective. Messenger 3(1-2):27-34

52. Higashida $\mathrm{H}$ et al (2011) CD38 gene knockout juvenile mice: a model of oxytocin signal defects in autism. Biol Pharm Bull 34(9):1369-1372 
53. Lambert RC et al (1994) A rise in the intracellular $\mathrm{Ca}^{2+}$ concentration of isolated rat supraoptic cells in response to oxytocin. J Physiol (Lond) 478:275-287

54. Fill M, Copello JA (2002) Ryanodine receptor calcium release channels. Physiol Rev 82(4):893-922

55. Endo M (2009) Calcium-induced calcium release in skeletal muscle. Physiol Rev 9(4):1153-1176

56. Numa $\mathrm{S}$ et al (1990) Molecular insights into excitation-contraction coupling. Cold Spring Harb Symp Quant Biol 55:1-7

57. Boittin FX et al (2003) Vasodilation by the calcium-mobilizing messenger cyclic ADP-ribose. J Biol Chem 278(11):9602-9608

58. Higashida $\mathrm{H}$ et al (2007) Overexpression of human CD38/ADPribosyl cyclase enhances acetylcholine-induced $\mathrm{Ca}^{2+}$ signalling in rodent NG108-15 neuroblastoma cells. Neurosci Res 57(3):339-346

59. Sternfeld L et al (2003) Hormonal control of ADP-ribosyl cyclase activity in pancreatic acinar cells from rats. J Biol Chem 278(36):33629-33636

60. Graeff RM et al (1998) Cyclic GMP-dependent and -independent effects on the synthesis of the calcium messengers cyclic ADPribose and nicotinic acid adenine dinucleotide phosphate. J Biol Chem 273(1):118-125

61. Kim SY, Cho B, Kim UH (2010) CD38-mediated $\mathrm{Ca}^{2+}$ signaling contributes to angiotensin II-induced activation of hepatic stellate cells: attenuation of hepatic fibrosis by CD38 ablation. J Biol Chem 285(1):576-582

62. Rah SY et al (2005) Activation of CD38 by interleukin-8 signaling regulates intracellular $\mathrm{Ca}^{2+}$ level and motility of lymphokine-activated killer cells. J Biol Chem 280(4):2888-2895

63. Kim UH (2014) Multiple enzymatic activities of CD38 for $\mathrm{Ca}^{2+}$ signaling messengers. Messenger 3(1-2):6-14

64. De Flora A et al (2004) Autocrine and paracrine calcium signaling by the CD38/NAD ${ }^{+} /$cyclic ADP-ribose system. Ann N Y Acad Sci 1028:176-191

65. Franco L (2001) Paracrine roles of $\mathrm{NAD}^{+}$and cyclic ADP-ribose in increasing intracellular calcium and enhancing cell proliferation of 3 T3 fibroblasts. J Biol Chem 276(24):21642-21648

66. Zhao YJ, Lam CM, Lee HC (2012) The membrane-bound enzyme CD38 exists in two opposing orientations. Sci Signal 5(241):ra67

67. Zhao YJ et al (2015) Determinations of the membrane orientation of a calcium signaling enzyme CD38. Biochim Biophys Acta 1853(9):2095-2103

68. Higashida H et al (1999) Sympathetic potentiation of cyclic ADPribose formation in rat cardiac myocytes. $\mathrm{J}$ Biol Chem 274(47):33348-33353

69. Liu HX et al (2012) Intracellular calcium concentrations regulated by cyclic ADP-ribose and heat in the mouse hypothalamus. Messenger 1(2):150-159

70. Faouzi M, Penner R (2014) TRPM2. Handb Exp Pharmacol 222:403-426

71. Uchida K, Tominaga M (2014) The role of TRPM2 in pancreatic $\beta$-cells and the development of diabetes. Cell Calcium 56(5):332-339
72. Beck A et al (2006) Nicotinic acid adenine dinucleotide phosphate and cyclic ADP-ribose regulate TRPM2 channels in T lymphocytes. FASEB J 20(7):962-964

73. Higashida $\mathrm{H}$ et al (2007) Cyclic ADP-ribose as a universal calcium signal molecule in the nervous system. Neurochem Int 51(2-4):192-199

74. Nirenberg $M$ et al (1983) Modulation of synapse formation by cyclic adenosine monophosphate. Science 222(4625):794-799

75. Amina $S$ et al (2010) Intracellular calcium elevation induced by extracellular application of cyclic-ADP-ribose or oxytocin is temperature-sensitive in rodent NG108-15 neuronal cells with or without exogenous expression of human oxytocin receptors. J Neuroendocrinol 22(5):460-466

76. Ceni $\mathrm{C}$ et al (2006) The CD38-independent ADP-ribosyl cyclase from mouse brain synaptosomes: a comparative study of neonate and adult brain. Biochem J 395(2):417-426

77. Higashida $\mathrm{C}$ et al (2013) Dopamine-induced regulation and deregulation of the catabolism of cyclic ADP-ribose, an intrinsic mTOR signal inhibitor, during development in the rodent striatum. Messenger 2(1-2):33-43

78. Salmina AB et al (2010) CD38/cyclic ADP-ribose system: a new player for oxytocin secretion and regulation of social behavior. J Neuroendocrinol 22(5):380-392

79. Modi ME, Young LJ (2012) The oxytocin system in drug discovery for autism: animal models and novel therapeutic strategies. Horm Behav 61(3):340-350

80. Munesue $\mathrm{T}$ et al (2010) Two genetic variants of CD38 in subjects with autism spectrum disorder and controls. Neurosci Res 67(2):181-191

81. Feldman R (2015) Sensitive periods in human social development: new insights from research on oxytocin, synchrony, and high-risk parenting. Dev Psychopathol 27(2):369-395

82. Krol KM et al (2015) Genetic variation in CD38 and breastfeeding experience interact to impact infants'attention to social eye cues. Proc Natl Acad Sci USA 112(39):E5434-E5442

83. Chang SC et al (2014) Are genetic variations in OXTR, AVPR1A, and CD38 genes important to social integration? Results from two large USA cohorts. Psychoneuroendocrinology 39:257-368

84. Hovey D et al (2014) Associations between oxytocin-related genes and autistic-like traits. Soc Neurosci 9(4):378-386

85. Ebstein RP et al (2011) Are retinoids potential therapeutic agents in disorders of social cognition including autism? FEBS Lett 585(11):1529-1536

86. Sauer C et al (2012) Effects of a common variant in the CD38 gene on social processing in an oxytocin challenge study: possible links to autism. Neuropsychopharmacology 37(6):1474-1482

87. Algoe SB, Way BM (2014) Evidence for a role of the oxytocin system, indexed by genetic variation in $\mathrm{CD} 38$, in the social bonding effects of expressed gratitude. Soc Cogn Affect Neurosci 9(12):1855-1861

88. Watanabe $\mathrm{T}$ et al (2015) Clinical and neural effects of six-week administration of oxytocin on core symptoms of autism. Brain 138(11):3400-3412 